\title{
Fungal Symbionts as Manipulators of Plant Reproductive Biology
}

\author{
Alexander M. Gorischek, ${ }^{1}$ Michelle E. Afkhami, ${ }^{2}$ Elizabeth K. Seifert, ${ }^{1}$ and Jennifer A. Rudgers ${ }^{1,3, *}$ \\ 1. Department of Ecology and Evolutionary Biology, Rice University, Houston, Texas 77005; 2. Department of Evolution and Ecology, \\ University of California, Davis, California 95616; 3. Department of Biology, University of New Mexico, Albuquerque, New Mexico 87131 \\ Submitted June 5, 2012; Accepted October 25, 2012; Electronically published February 15, 2013 \\ Dryad data: http://dx.doi.org/10.5061/dryad.84c26.
}

\begin{abstract}
AвSTRACT: Symbioses have shaped the evolution of life, most notably through the fixation of heritable symbionts into organelles. The inheritance of symbionts promotes mutualism and fixation by coupling partner fitness. However, conflicts arise if symbionts are transmitted through only one sex and can shift host resources toward the sex through which they propagate. Such reproductive manipulators have been documented in animals with separate sexes but not in other phyla or sexual systems. Here we investigated whether the investment in male relative to female reproduction differed between hermaphroditic host plants with versus without a maternally inherited fungal symbiont. Plants with the fungus produced more seeds and less pollen than plants lacking the fungus, resulting in an $\sim 40 \%$ shift in functional gender and a switch from male-biased to female-biased sex allocation. Given the ubiquity of endophytes in plants, reproductive manipulators of hermaphrodites may be widespread in nature.
\end{abstract}

Keywords: mutualism, parasitism, epichloae, sex allocation, sex ratio, Elymus.

\section{Introduction}

In sexually reproducing organisms, selection should favor the balance of investments between male and female lineages that maximizes long-term reproductive success (de Jong and Klinkhamer 2005; Sinclair et al. 2012). However, uniparentally inherited symbionts may shift this balance to their own advantage by increasing investment toward the sex through which they propagate (Hamilton 1967; Turelli 1994). This shift may occur despite selection for mutualism caused by the coupling of host and symbiont fitness during the process of vertical transmission (Bull and Rice 1991; Herre et al. 1999; Sachs et al. 2004). For example, a symbiont transmitted exclusively through the maternal host lineage could gain a fitness advantage by directing host investment toward female offspring and

* Corresponding author; e-mail: jrudgers@unm.edu.

Am. Nat. 2013. Vol. 181, pp. 562-570. (C) 2013 by The University of Chicago. 0003-0147/2013/18104-53885\$15.00. All rights reserved.

DOI: $10.1086 / 669606$ away from male offspring. Conflict arises because host genes are passed equally through successful male and female offspring, while symbiont genes are passed only through female offspring. Such conflicts, manifested as male killing, cytoplasmic incompatibility, feminization of male embryos, and induction of parthenogenesis, have been documented in species with separate sexes (gonochorists), particularly arthropods and crustaceans that host maternally transmitted Wolbachia bacteria (Werren et al. 2008; Engelstadter and Hurst 2009). Reproductive manipulation of hermaphrodites, which have both male and female sex organs, is likely facilitated by the plasticity of parental investment in male versus female gametes but remains unexplored (Schärer 2009).

Symbioses with fungal endophytes are pervasive in plants, and uniparental transmission through the maternal lineage is common (Bacon and White 2000; Rodriguez et al. 2009). Fungal endophytes reside in aboveground plant tissues and can impart drought tolerance, resistance to herbivores and pathogens, and enhanced competitiveness (Cheplick and Faeth 2009; Schardl 2010). Endophytes confer these benefits to the host plant but might also increase their own fitness by manipulating host resources away from pollen and toward seeds. Therefore, we evaluated the reproductive investments of symbiotic and symbiont-free Elymus virginicus (Virginia wild rye, Poaceae), a perennial grass that is widespread in North America and commonly hosts the endophytic fungus Epichlöe elymi (Rudgers et al. 2009; Saha et al. 2009).

\section{Methods \\ Design}

We compared reproductive investments among three groups of Elymus virginicus plants: symbiotic offspring of symbiotic parents (abbreviated “,++ , $n=84$ ), symbiont-free offspring of symbiotic parents produced by im- 
perfect vertical transmission of the endophyte (first-generation symbiont-free ",$+- " n=37$ ), and offspring of host lineages lacking the endophyte in the native field population (multigeneration symbiont-free " -- ," $n=$ 48).

\section{Parental Generation}

In July 2006, we collected seeds from 60 naturally occurring individuals of E. virginicus at the Stephen F. Austin Experimental Forest (Nacogdoches, TX), where the endophyte occurs in $\sim 25 \%$ of host plant individuals. Seeds were germinated in wet sand at $5^{\circ} \mathrm{C}$, then transplanted as seedlings into $115-\mathrm{mL}$ pots (Conetainers, Stuewe and Sons, Canby, OR) filled with ProMix BX potting soil (Premier Horticulture, Quakertown, PA). We grew these plants in the greenhouse $\left(\sim 23^{\circ} \mathrm{C}\right.$, daily watering) for $\sim 3$ months, then produced clones of these plants consisting of 1-3 tillers each. On November 9 and 10, 2007, we planted $100 \%$ symbiotic or symbiont-free populations into a common garden at the forest. Each population consisted of 20 unique plant genotypes ( $n=5$ populations per endophyte status; 200 plants total).

\section{Greenhouse Experiment}

From June 26 to August 6, 2008, we collected seeds from experimental populations. Seeds were germinated in wet sand at $5^{\circ} \mathrm{C}$, and seedlings were transplanted into $1-\mathrm{L}$ pots of soil. We grew these progeny of our experimental field populations in the greenhouse $\left(\sim 23^{\circ} \mathrm{C}\right.$, daily watering $)$ and treated them monthly with $2 \%$ insecticidal soap to control aphids (Garden Safe, Spectrum Brands, Atlanta).

\section{Endophyte Detection}

We scored all plants for endophyte presence using light microscopy to examine thin sections of inner leaf sheath stained with lactophenol cotton blue (Bacon and White 1994). The endophyte was identified as Epichlöe elymi (Clavicipitaceae) based on intron regions of the genes encoding $\beta$-tubulin (tub2) and translation elongation factor $1-\alpha$ (tefl; Schardl 2010; C. Young and C. Schardl, unpublished data). Epichlöe can reproduce both sexually via stromata (fungal reproductive structures that sterilize inflorescences) and asexually via seed transmission; however, no stromata were produced in our natural population, experimental field plots, or greenhouse-grown plants, which is not uncommon in this host species (Saha et al. 2009).

\section{Plant Investment}

On average, flowering plants produced three inflorescences and 166 anthers. We collected anthers opportunistically from mature inflorescences and allowed them to dehisce onto sterile, plastic plates. Pollen grains from one mature anther per plant were captured photographically (Adobe Photoshop, ver. 9.0.2, Adobe Systems, Mountain View, $\mathrm{CA}$ ) and counted using particle analysis (ImageJ, US National Institutes of Health, Bethesda, MD). We estimated total pollen production per plant as the product of the per-anther pollen count, the number of pollen-producing florets, and the number of anthers per floret ( $=3$ anthers). Seeds were collected upon maturation and weighed to the nearest 0.001 g. Plants were harvested on October 4, 2009, by clipping shoots at the soil surface and washing roots through a 1-mm sieve (US standard sieve no. 18, Soil Test, Lake Bluff, IL). Tillers and roots were dried to constant mass $\left(60^{\circ} \mathrm{C}\right)$ and weighed to the nearest $0.001 \mathrm{~g}$. Mature inflorescences were harvested separately for seed counting and were not included in vegetative biomass measurements. Of the 571 inflorescences produced by the experimental plants, 10 remained immature at the time of plant harvest; we estimated seed production for these immature inflorescences as the average number of seeds produced by the mature inflorescences from the same plant.

For each plant individual (i), functional gender was calculated following Lloyd (1980): $G_{i}=d_{i} /\left[d_{i}+l_{i} E\right]$, where $d_{i}=$ the number of seeds, $l_{i}=$ the number of pollen grains, and $E=$ the equivalency factor used to adjust the fitness of pollen to that of seeds, $E=\sum d_{i} / \sum l_{i}$. For analysis of reproductive investments, we used one-way ANOVA with the fixed effect of endophyte status $(++$, +- , or -- ) (SAS ver. 9.1, SAS Institute, Cary, NC), followed by post hoc Tukey HSD tests. Most variables were transformed to satisfy the assumptions of homogeneity of variance and normality (table 1; Dryad data repository, doi:10.5061/dryad.84c26).

\section{Pollen and Seed Viability}

Because seed or pollen viability may be affected by endophyte symbiosis, the realized functional gender (corrected by the viability of seeds and pollen) may differ from the seed to pollen ratio. We had two sources of information on seed viability. First, we collected a subset of seeds from the experimental field populations in 2009 (E+ [endophyte present] $n=35, \mathrm{E}-$ [endophyte absent] $n=64$ seeds). Seeds were surface sterilized in $50 \%$ bleach and then plated onto petri plates of $1 \%$ water agar $($ mean $=$ 5.5 seeds per plate). For cold stratification, we sealed plates with Parafilm and refrigerated them at $4^{\circ} \mathrm{C}$ from November 18,2009 , to January 4,2010 . We then placed cold- 
Table 1: Transformations, $F$ ratios, degrees of freedom (df), and $P$ values from one-way ANOVA for variables reported in figures 1 and 2 and in the text

\begin{tabular}{|c|c|c|c|c|}
\hline Response, scale & Transformation & $F$ & df & $P$ \\
\hline \multicolumn{5}{|l|}{ Lloyd's $G_{i}$ : } \\
\hline Per plant & None & 30.84 & 2,166 & $<.0001$ \\
\hline \multicolumn{5}{|l|}{ Tillers: } \\
\hline Per plant & $(x+0.5)^{\wedge} 0.5$ & 30.32 & 2,230 & $<.0001$ \\
\hline $\begin{array}{l}\text { Per gram above- } \\
\text { ground biomass }\end{array}$ & \multicolumn{3}{|c|}{ Per gram above- } & $<.0001$ \\
\hline \multicolumn{5}{|l|}{ Inflorescences: } \\
\hline Per plant & $(x+0.5)^{\wedge} 0.5$ & 18.07 & 2,230 & $<.0001$ \\
\hline Per tiller & $\log (x+0.1)$ & .32 & 2,202 & .7243 \\
\hline \multicolumn{5}{|l|}{ Florets: } \\
\hline Per plant & $(x+0.05)^{\wedge} 0.5$ & 6.87 & 2,230 & .0013 \\
\hline Per inflorescence & $(x+0.05)^{\wedge} 0.5$ & 16.18 & 2,202 & $<.0001$ \\
\hline \multicolumn{5}{|l|}{ Pollen grains: } \\
\hline Per plant & $x \wedge 0.3$ & 4.77 & 2,166 & .0097 \\
\hline Per bud & None & 27.84 & 2,166 & $<.0001$ \\
\hline \multicolumn{5}{|l|}{ Seeds: } \\
\hline Per plant & $(x+0.05)^{\wedge} 0.5$ & 13.5 & 2,230 & $<.0001$ \\
\hline Per bud & None & 21.8 & 2,195 & $<.0001$ \\
\hline \multicolumn{5}{|l|}{ Seed mass: } \\
\hline Per plant & $\log (x+.0001)$ & 6.3 & 2,193 & .0022 \\
\hline Per seed & None & 1.35 & 2,193 & .2610 \\
\hline \multicolumn{5}{|l|}{ Biomass: } \\
\hline Aboveground & None & 5.93 & 2,230 & .0031 \\
\hline Belowground & None & 6.78 & 2,228 & .0014 \\
\hline Total per plant & None & 5.25 & 2,228 & .0059 \\
\hline
\end{tabular}

stratified plates in the greenhouse to allow for germination. The germination status of each seed was scored weekly for 9 weeks; no new seedlings had germinated after week 6 . We tested whether the endophyte status of the experimental plot was associated with an altered probability of germination (log linear model on binomial data) or rate of germination ( $\log ($ no. of days to germination)) using general linear models (SAS ver. 9.1).

In addition to data from the laboratory, we recorded recruitment rates in the experimental field populations every year for 4 years (2009-2012). Each year, we estimated total seed production in the plot and marked every new seedling that recruited. The plots lacked a prior seed bank for E. virginicus; therefore, we could be confident that all recruits originated from the experimental plants. We calculated the recruitment rate $(=$ no. of recruits per plot in year $t+1 /$ no. of seeds produced per plot in year $t$ for each year $(t=2008-2011)$. We also calculated recruitment rate assuming a persistent seed bank $(=$ no. of recruits per plot in year $t+1 /$ [no. of seeds produced per plot in all years prior to $t+1-$ no. of recruits per plot in all years prior to $t+1])$. We tested for an effect of endophyte status of the field population, year, and endophyte $\times$ year on the recruitment rate ( $n=5$ plots per endophyte status) using a general linear mixed model with plot as a random effect, nested within endophyte status (SAS ver. 9.1). Less conservative models that excluded the plot factor returned similar and did not reduce the fit of the model to the data (corrected Akaike Information Criterion $<2$ in all cases), indicating that plot identity explained little variation in the data.

Data on pollen viability could refine estimates of functional gender; however, for several reasons, we did not pursue estimates of pollen viability in this study. In grasses, pollen viability often declines rapidly following anther dehiscence (Dafni and Firmage 2000). In some species of Elymus and the related genus Leymus, pollen loses viability after just 3-4 h (Cicin 1954; Huang et al. 2004). Second, available staining methods are often ineffective for assessments of grass pollen viability (Dafni and Firmage 2000; Wang et al. 2004). Third, if effects of endophyte symbiosis on pollen viability were to alter our conclusions, the endophyte must have opposing effects on pollen viability (which would have to increase) and pollen grain number (which was reduced). Because the endophyte does not occur in pollen grains, we suspect an endophytemediated increase in pollen viability is unlikely.

\section{Results}

Plants with the endophyte showed greater relative investment in female function than plants lacking the endophyte. To control for plant genetic background, we first compared naturally symbiotic plants to plants that lost their symbionts during imperfect maternal transmission of the endophyte (see Afkhami and Rudgers 2008; Gundel et al. 2011). Thus, both symbiotic plants and first-generation symbiont-free plants were progeny of the same pool of symbiotic parents $(++$ treatment vs. +- treatment). The functional gender of plants with the endophyte was $25 \%$ more female biased than first-generation symbiont-free plants. Furthermore, the functional gender of plants with the endophyte was female biased $(=0.56 ; 0.5$ is equal investment, $<0.5$ indicates male bias, $>0.5$ indicates a female bias), whereas the functional gender of symbiont-free plants was male biased ( $=0.45$; fig. 1 ; table 1$)$.

Shifts in the functional gender metric at the scale of the whole plant corresponded to differential allocation patterns during particular stages of plant reproductive development. Specifically, symbiotic plants matured $25 \%$ more seeds per floret (fig. $2 A$ ) but produced $44 \%$ less total pollen and $25 \%$ less pollen per floret than symbiont-free plants (fig. 2B). Plants with the endophyte also made fewer florets per inflorescence (fig. 2C), which contributed to the overall reduction in male function. The endophyte did not mediate a trade-off between the size and the number of seeds (Gundel et al. 2012) because endophyte presence 


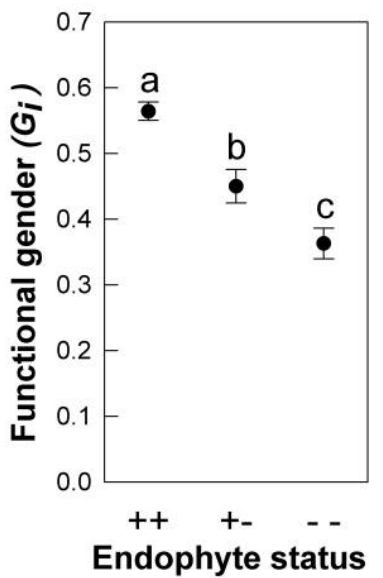

Figure 1: Elymus virginicus plants with the endophyte Epichlöe elymi show more female-biased functional gender relative to plants without the endophyte $\left(F_{2,166}=30.8, P<.0001, r^{2}=0.27\right)$. Paired symbols indicate endophyte status, with symbiotic plants represented by "++," plants that lost the endophyte during maternal transmission by ",+- , and multigeneration symbiont-free plant lineages by "--." The first sign represents the parent and the second the offspring, with "+" indicating endophyte symbiosis and "-" indicating a lack thereof. Circles with bars indicate means \pm SE. Different letters show significant differences following a post hoc Tukey HSD test.

did not significantly influence average seed mass (fig. $2 D$ ). Symbiotic plants produced $31 \%$ more inflorescences (fig. $2 E$ ) and $19 \%$ more vegetative tillers (fig. $2 F$ ) but made less total vegetative biomass (mean $\pm \mathrm{SE}, 1.98 \pm 0.05 \mathrm{~g}$ ) than symbiont-free plants $(2.39 \pm 0.13 \mathrm{~g}$, Tukey HSD, $P<.05)$. Vegetative biomass was not correlated with the functional gender of individual plants $\left(r^{2}=0.004\right.$, $P=.43$ ), indicating that any effects of the symbiont did not manifest as a consequence of differences in plant size.

We also compared symbiotic plant lineages to lineages derived from symbiont-free maternal plants (i.e., multigeneration symbiont-free plants). Functional gender was $55 \%$ more female biased for symbiotic plants (fig. 1), reflecting $107 \%$ more total seeds (fig. $2 A$ ) and $25 \%$ fewer total pollen grains (fig. $2 B$ ). Plants from lineages with the endophyte matured $47 \%$ more seeds per floret (fig. $2 A$ ) and produced $29 \%$ fewer pollen grains per floret (fig. $2 B$ ) than plants from lineages lacking the endophyte. The endophyte was not associated with significant differences in pollen grain size (mean area captured photographically \pm $\mathrm{SE}$, symbiotic $=1,400 \pm 30 \mu \mathrm{m}^{2}$, multigeneration symbiont-free $\left.=1,450 \pm 20 \mu \mathrm{m}^{2}, F_{1,28}=1.5, P>.23\right)$. The vegetative biomass of symbiotic plants (mean $\pm \mathrm{SE}$, $1.98 \pm 0.05 \mathrm{~g}$ ) did not differ significantly from that of multigeneration symbiont-free plants (mean $\pm \mathrm{SE}$, $2.15 \pm 0.10 \mathrm{~g}$, Tukey HSD, $P>.05$ ); however, symbiotic plants made $38 \%$ more florets, $81 \%$ more inflorescences, and $43 \%$ more vegetative tillers (fig. 2 ).

Both types of symbiont-free plants produced similar quantities of seeds per floret, pollen per plant, pollen per floret, inflorescences per tiller, and tillers per gram biomass (fig. 2), but multigeneration symbiont-free plants were functionally more male than first-generation symbiontfree plants (fig. 1) because they produced fewer total seeds (fig. 2A). Dissimilarities between the two types of symbiont-free plants may reflect underlying genetic variation between plant lineages or differences in maternal provisioning between symbiotic and symbiont-free parents. However, differences were not environmentally driven because all plants were propagated in a common environment for two generations.

Because seed and pollen viability may differ with endophyte symbiosis, the realized functional gender (corrected by viability of each) may differ from the seed to pollen ratio measured here. Although we were unable to quantify pollen viability, results for seed viability were consistent with the hypothesis that the endophyte increases plant allocation to female function. In the laboratory, seeds with the endophyte germinated, on average, 3 days faster than seeds without the endophyte $(++$ mean $\pm \mathrm{SE}=$ $13.9 \pm 0.6$ days to germinate, -- mean $=16.8 \pm 0.6$ days; $\left.F_{1,87}=9.7, P<.003\right)$. However, over the course of 9 weeks, symbiont-free seeds were just as likely to germinate as symbiotic seeds $(++$ mean $\pm \mathrm{SE}=89 \% \pm$ $5 \%$ of seeds germinated, -- mean $=91 \% \pm 4 \%$; $\left.\chi^{2}=0.1, P=.748\right)$. Experimental field populations with the endophyte had a higher rate of recruitment (backtransformed least squares mean $[95 \% \mathrm{CI}]=0.47[0.20$, $0.84]$ ) than symbiont-free populations (mean $=0.22$ $[0.05,0.50])$; however, this difference was not statistically significant $\left(F_{1,8}=2.2, P=.18\right)$. Symbiotic populations also had higher, but not significantly different, recruitment rates when a persistent seed bank was incorporated, which reduced the overall rate of recruitment by increasing the size of the seed pool (back-transformed mean recruitment rate $[95 \% \mathrm{CI}] ; \mathrm{E}+=0.07[0.04,0.11] ; \mathrm{E}-=0.05[0.02$, 0.09 ]; $\left.F_{1,8}=0.8, P=.411\right)$. In field populations, we detected a strong effect of year for both recruitment models (without seed bank, $F_{1,24}=4.4, P=.014$; with seed bank $\left.F_{1,24}=9.5, P<.001\right)$, demonstrating that the models had sufficient statistical power. There were no statistically significant interactions between endophyte status and year (without seed bank, $F_{1,24}=0.7, P=.593$; with seed bank $F_{1,24}=1.2, P=.349$ ).

\section{Discussion}

The presence of a fungal endophyte in Elymus virginicus was associated with a significant shift in plant functional 

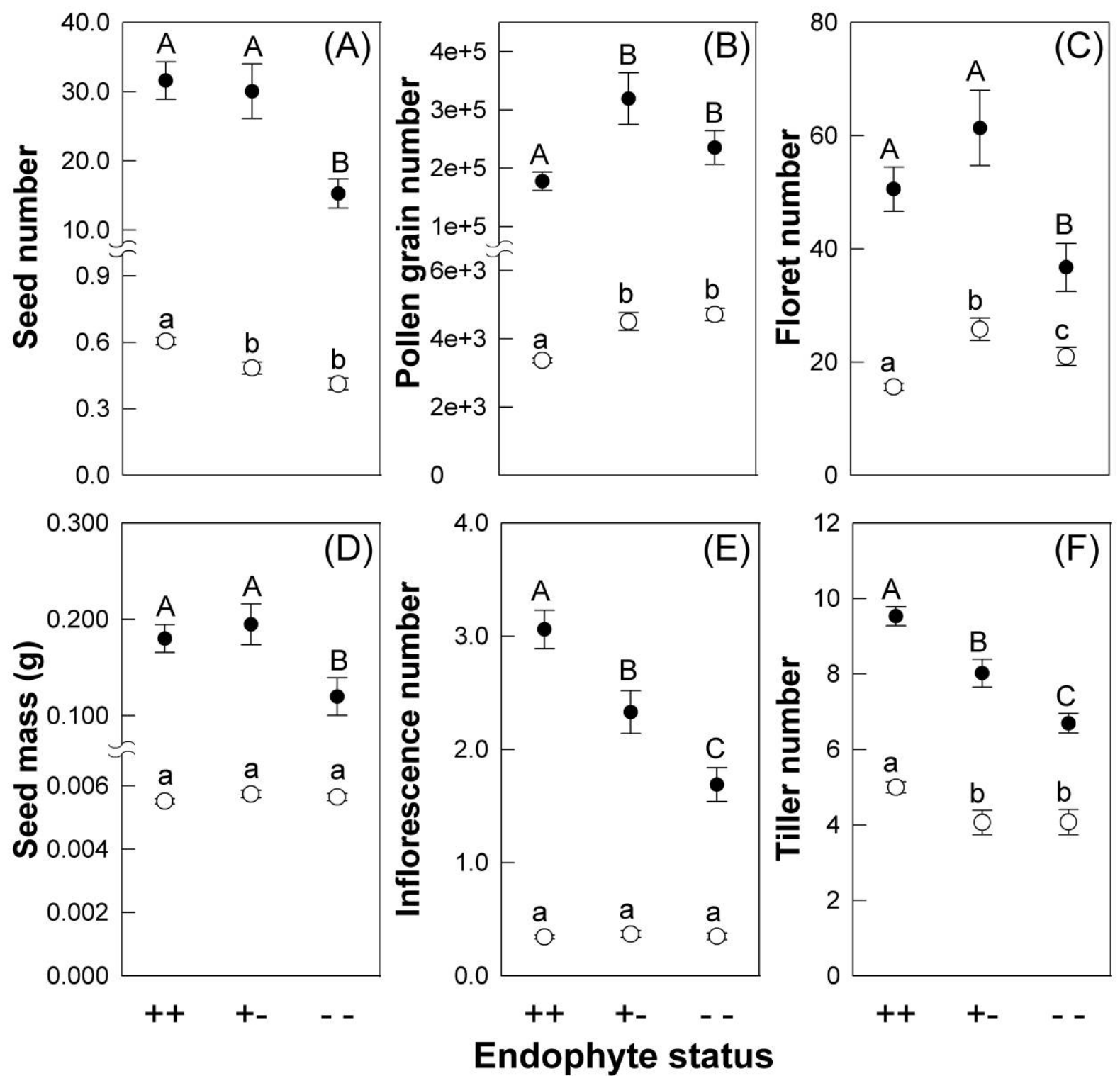

Figure 2: Effects of the Epichlöe elymi endophyte on vegetative and reproductive allocation of Elymus virginicus plants. Paired symbols show endophyte status as described in figure 1. Symbols marked by different letters differed significantly following a post hoc Tukey HSD test. Filled circles and uppercase letters refer to per-plant means \pm SE. Open circles and lowercase letters refer to means \pm SE for seeds matured per floret $(A)$, pollen produced per floret $(B)$, florets per inflorescence $(C)$, seed mass per seed $(D)$, inflorescences per tiller $(E)$, and tillers per gram aboveground biomass $(F)$. Table 1 presents $F$ ratios, df, and $P$ values.

gender, characterized by reduced plant investment in pollen and increased investment in seeds. Environmental conditions, such as nutrients, water, and light availability, have been estimated to cause from $30 \%$ to upward of $250 \%$ difference in reproductive allocation in plants (Freeman et al. 1981; Vitale et al. 1987; Koelewijn and Hunscheid 2000; Stehlik et al. 2008; Friedman and Barrett 2011). Thus, the magnitude of change in E. virginicus functional gender was well within the range of effects reported for other factors altering reproductive allocation in plants. Our results demonstrate that microbial symbionts deserve greater consideration in empirical tests of plant sex allocation. We also hope to spark the development of new theory predicting the evolutionary dynamics of reproductive manipulators in a broader range of organisms, including hermaphroditic hosts. 


\section{Mechanisms Underlying Reproductive Manipulation}

Insights into the mechanisms and dynamics of symbiontmediated reductions in pollen production may be gained from studies of nuclear-cytoplasmic male sterility (CMS) in plants, which has been documented in $>150$ species and is a primary cause of gynodioecy (plant populations composed of females and hermaphrodites; Hanson 1991). CMS can occur when mitochondrial genes encode proteins that suppress pollen production, and male sterility has been associated with reactive oxygen species produced by mitochondria (Chase 2007; Peng et al. 2010). Reactive oxygen species are also generated by fungal endophytes (Tanaka et al. 2006; Eaton et al. 2010; Hamilton et al. 2012) and could be one mechanism underlying how endophytes influence pollen production. Further study of endophyte behavior in florets and ovules may shed new light on the mechanisms of interference with plant reproduction.

\section{Maintenance of Variation in Symbiont Frequency}

Here, we evaluated pollen and seed production for plants from symbiotic lineages, plants from symbiont-free lineages, and plants that had naturally lost their symbionts during imperfect vertical transmission in the previous generation. We suspect that symbiont-free lineages have persisted for a long time, as intermediate symbiont frequencies are not uncommon in grasses and often occur in Elymus species in particular (Rudgers et al. 2009). Although we do not know what mechanisms maintain variation in symbiont frequency in natural host populations, endophyte-mediated protection against herbivory does not appear to be a strong driver in this species (Crawford et al. 2010), nor does protection from drought (Rudgers and Swafford 2009). While the focus of empirical research has been on the fitness costs and benefits of symbiosis (Cheplick and Faeth 2009), symbionts can also be maintained at intermediate frequencies in host populations simply through high rates of imperfect vertical transmission, particularly if the fitness benefits conferred by symbionts are relatively small (Gundel et al. 2011; Yule et al., forthcoming). This may be the case in E. virginicus. In addition, models of CMS dynamics predict maintenance of the male sterility polymorphism due to negative frequency-dependent selection (Bailey and Delph 2007). If female plants have even a small fitness advantage, CMS will increase in the population until seed production becomes constrained by the pollen supply (Charlesworth 1981). Frequencydependent selection constrained by the pollen supply may similarly explain why endophytes often occur in less than $100 \%$ of host individuals and vary widely in their prev- alence among host populations and species (Rudgers et al. 2009).

\section{Limitations of This Study}

Our results are consistent with the hypothesis that endophytes function as reproductive manipulators; however, it remains possible that differences in reproductive allocation are due, at least in part, to plant genotype. For example, the success of vertical transmission could depend on the genotype of the seed. Future work inoculating seedlings that are full sibs would further disentangle plant genotype and endophyte effects, although inoculation success could also be genotype specific. Alternatively, clones of symbiotic plants could be subjected to fungicide to eliminate the endophyte (e.g., Faeth 2009), provided that nontarget effects of the chemicals can be ruled out.

A second limitation is the lack of data on pollen viability. Ultimately, a combination of several approaches, for example, measures of respiration and pollen chemistry, viability staining, in vitro and in vivo germination estimates, and hand pollinations or paternity analysis to measure capacity to effect seed set, would refine estimates of plant functional gender (Dafni and Firmage 2000). Importantly, however, if the effects of endophyte symbiosis on pollen viability were to alter our conclusions, then the endophyte must reduce pollen grain number, as we have shown here, but increase pollen viability. Given the selective advantage to an endophyte of reducing plant investment in pollen, it seems more likely that the endophyte would reduce, rather than increase, pollen viability. Overall, due to the variety of factors that can influence pollen viability, we think that sophisticated estimates of pollen viability would have strengthened our conclusions to a relatively small degree.

\section{Male-Biased Sex Allocation in Wind-Pollinated Plants}

Reproductive manipulation is a strong hypothesis for the female-biased functional gender observed in symbiotic plants, but symbiont-free plants were male biased. Why? There are a number of factors that predict an optimal functional gender that deviates from equal investment. Functional gender varies with the degree and type of selfcompatibility (Brunet 1992; de Jong et al. 1999), the number of available mates (Schärer 2009), the size of the floral display (Karron and Mitchell 2012), and the shapes of the fitness gain curves for pollen versus seeds (Charlesworth and Charlesworth 1981; Charnov 1982; Brunet 1992). Gain curves characterize the increase in male (or female) fitness as a function of increased plant investment in pollen (or seeds). For example, if the gain curve for pollen is linear, as is expected for wind-pollinated plants, and the female 
gain curve is saturating (e.g., short seed dispersal distances increase local competition at high levels of seed investment), the optimal functional gender will be male biased (Charlesworth and Charlesworth 1981; Charnov 1982; de Jong et al. 2002). We have often observed tight clusters of seedlings germinating from $E$. virginicus inflorescences that fall next to parent plants; therefore, a saturating female gain curve is a possibility in this wind-pollinated species. In contrast to these gain curve differences, selfing should shift functional gender toward female investment, and the type of selfing (within the same flower or between flowers on the same individual) can influence the amount of bias (e.g., de Jong et al. 1999). Although the genus Elymus is known to be self-compatible and includes autogamous taxa (Love and Connor 1982; Jensen et al. 1990), we do not know how much or what type of selfing occurs in our E. virginicus population. Empirically, it is not uncommon for wind-pollinated plants to have male-biased functional gender (McKone et al. 1998; Friedman and Barrett 2011). Thus, it is possible that our observation of male-biased functional gender in symbiont-free plants reflects the optimal investment strategy to maximize plant fitness.

\section{Future Directions for Research on Symbionts and Plant Reproductive Biology}

In addition to the manipulation of functional gender detected here, plant reproductive biology may be altered by endosymbionts in other, possibly subtle, ways. For instance, symbiont-mediated modifications to inflorescence or floret architecture could alter the distance and rate of pollen dispersal and pollen capture. Although symbiont effects on reproductive architecture have yet to be explored, experiments have revealed important contributions of inflorescence architecture to pollination in grasses (Friedman and Harder 2004). The effects of symbionts on inflorescence height may be of particular interest because height influences both seed and pollen dispersal distances, which can then affect optimal functional gender (Sakai and Sakai 2003). In addition, symbionts could influence flowering phenology (J. Rudgers and A. Gorischek, unpublished data), inbreeding rates (Botham et al. 2009), the relative performance of male and female plants (Eppley et al. 2009), or plant mate choice, as in incompatibilityinducing Wolbachia. Altogether, such effects could alter the genetic structure and fitness of plant populations and possibly drive the evolution of plant sexual systems.

\section{Applied Significance to Restoration and Agronomy}

Many endophyte-hosting grasses, including E. virginicus, are widely used for ecological restoration (Sanderson $\mathrm{e} \rightarrow$ al. 2004). Furthermore, Elymus is a close relative of im- portant crop species, including barley, wheat, and rye. The increased seed production of symbiotic plants demonstrated here, along with the enhanced vegetative growth, survival, herbivore resistance, and drought tolerance of symbiotic plants reported elsewhere (Cheplick and Faeth 2009; Rudgers and Swafford 2009), could boost establishment of host populations grown for food or restoration. Preservation of endophyte viability in seeds requires proper storage techniques (e.g., Welty et al. 1987), and failure to restore the symbiotic status of host populations could have negative consequences for restoration and revegetation efforts, as well as for crop production.

\section{Conclusion}

We have shown that, rather than being a passive occupant, the symbiotic fungus Epichlöe elymi may actively manipulate its host plant, causing a distortion of reproductive investment away from pollen and toward seeds. Fungal and bacterial endophytes are nearly ubiquitous in plants (Bacon and White 2000; Rodriguez et al. 2009), and recent studies are turning up more and more cases of their maternal inheritance (e.g., Ralphs et al. 2011; Hardoim et al. 2012). Thus, these microbial symbionts are important to consider as agents of selection on plant reproductive strategies.

\section{Acknowledgments}

We thank D. Campbell, K. Clay, K. Rice, S. Strauss, M. Turelli, and K. Whitney for comments on the manuscript and members of the Rudgers and Whitney Labs for assistance with plant maintenance and data collection. Funding provided by the National Science Foundation's Division of Environmental Biology (grants 054278 and 1145588) and the Rice University Godwin Assistant Professorship to J.A.R.

\section{Literature Cited}

Afkhami, M. E., and J. A. Rudgers. 2008. Symbiosis lost: imperfect vertical transmission of fungal endophytes in grasses. American Naturalist 172:405-416.

Bacon, C. W., and J. F. White. 2000. Microbial endophytes. Dekker, New York.

Bacon, C. W., and J. F. White Jr. 1994. Stains, media, and procedures for analyzing endophytes. Pages 47-56 in C. W. Bacon and J. F. White Jr., eds. Biotechnology of endophytic fungi of grasses. CRC, Boca Raton, FL.

$\rightarrow$ Bailey, M. F., and L. F. Delph. 2007. A field guide to models of sexratio evolution in gynodioecious species. Oikos 116:1609-1617.

Botham, R., C. L. Collin, and T.-L. Ashman. 2009. Plant-mycorrhizal fungus interactions affect the expression of inbreeding depression 
in wild strawberry. International Journal of Plant Sciences 170: 143-150.

$\rightarrow$ Brunet, J. 1992. Sex allocation in hermaphroditic plants. Trends ir. $\rightarrow$ Ecology and Evolution 7:79-84.

$\rightarrow$ Bull, J. J., and W. R. Rice. 1991. Distinguishing mechanisms for the evolution of cooperation. Journal of Theoretical Biology 149:6374 .

$\rightarrow$ Charlesworth, D. 1981. A further study of the problem of the maintenance of females in gynodioecious species. Heredity 46:27-39.

$\rightarrow$ Charlesworth, D., and B. Charlesworth. 1981. Allocation of resources to male and female functions in hermaphrodites. Biological Journal of the Linnean Society 15:57-74.

Charnov, E. L. 1982. The theory of sex allocation. Princeton University Press, Princeton, NJ.

$\rightarrow$ Chase, C. D. 2007. Cytoplasmic male sterility: a window to the worla of plant mitochondrial-nuclear interactions. Trends in Genetics 23:81-90.

Cheplick, G. P., and S. H. Faeth. 2009. Ecology and evolution of grass-endophyte symbiosis. Oxford University Press, Oxford.

Cicin, N. V. 1954. Elymus and its biological properties. Pages $377-$ 389 in Gosudarstvennoe Izdateljstvo Seljskohozjaistvennoi Literatury.

$\rightarrow$ Crawford, K. M., J. M. Land, and J. A. Rudgers. 2010. Fungal endophytes of native grasses decrease insect herbivore preference and performance. Oecologia (Berlin) 164:431-444.

$\rightarrow$ Dafni, A., and D. Firmage. 2000. Pollen viability and longevity: practical, ecological and evolutionary implications. Plant Systematics and Evolution 222:113-132.

de Jong, T. J., and P. G. L. Klinkhamer. 2005. Evolutionary ecology of plant reproductive strategies. Cambridge University Press, New York.

$\rightarrow$ de Jong, T. J., P. G. L. Klinkhamer, and M. C. J. Rademaker. 1999. How geitonogamous selfing affects sex allocation in hermaphrodite plants. Journal of Evolutionary Biology 12:166-176.

$\rightarrow$ de Jong, T. J., F. H. D. Van Batenburg, and J. van Dijk. 2002. Seed sex ratio in dioecious plants depends on relative dispersal of pollen and seeds: an example using a chessboard simulation model. Jour nal of Evolutionary Biology 15:373-379.

$\rightarrow$ Eaton, C. J., M. P. Cox, B. Ambrose, M. Becker, U. Hesse, C. L. Schardl, and B. Scott. 2010. Disruption of signaling in a fungal grass symbiosis leads to pathogenesis. Plant Physiology 153:17801794.

$\rightarrow$ Engelstadter, J., and G. D. D. Hurst. 2009. The ecology and evolution of microbes that manipulate host reproduction. Annual Review o $\rightarrow$ Ecology, Evolution, and Systematics 40:127-149.

$\rightarrow$ Eppley, S. M., C. A. Mercer, C. Haaning, and C. B. Graves. 2009. Sex-specific variation in the interaction between Distichlis spicata (Poaceae) and mycorrhizal fungi. American Journal of Botany $96 \rightarrow$ 1967-1973.

$\rightarrow$ Faeth, S. H. 2009. Asexual fungal symbionts alter reproductive allocation and herbivory over time in their native perennial gras $\rightarrow$ hosts. American Naturalist 173:554-565.

$\rightarrow$ Freeman, D. C., E. D. McArthur, K. T. Harper, and A. C. Blauer. 1981. Influence of environment on the floral sex-ratio of mon $\rightarrow$ oecious plants. Evolution 35:194-197.

$\rightarrow$ Friedman, J., and S. C. H. Barrett. 2011. Genetic and environmental control of temporal and size-dependent sex allocation in a winc $\rightarrow$ pollinated plant. Evolution 65:2061-2074.

$\rightarrow$ Friedman, J., and L. D. Harder. 2004. Inflorescence architecture and wind pollination in six grass species. Functional Ecology 18:851860.

Gundel, P. E., L. A. Garibaldi, M. A. Martinez-Ghersa, and C. M. Ghersa. 2012. Trade-off between seed number and weight: influence of a grass-endophyte symbiosis. Basic and Applied Ecology 13:32-39.

Gundel, P. E., J. A. Rudgers, and C. M. Ghersa. 2011. Incorporating the process of vertical transmission into understanding of hostsymbiont dynamics. Oikos 120:1121-1128.

Hamilton, C. E., P. E. Gundel, M. Helander, and K. Saikkonen. 2012. Endophytic mediation of reactive oxygen species and antioxidant activity in plants: a review. Fungal Diversity 54:1-10.

$\rightarrow$ Hamilton, W. D. 1967. Extraordinary sex ratios. Science 156:477488.

Hanson, M. R. 1991. Plant mitochondrial mutations and male sterility. Annual Review of Genetics 25:461-486.

Hardoim, P. R., C. C. P. Hardoim, L. S. van Overbeek, and J. D. van Elsas. 2012. Dynamics of seed-borne rice endophytes on early plant growth stages. PloS ONE 7:e30438.

Herre, E. A., N. Knowlton, U. G. Mueller, and S. A. Rehner. 1999. The evolution of mutualisms: exploring the paths between conflict and cooperation. Trends in Ecology and Evolution 14:49-53.

$\rightarrow$ Huang, Z. H., J. M. Zhu, X. J. Mu, and J. X. Lin. 2004. Pollen dispersion, pollen viability and pistil receptivity in Leymus chinensis. Annals of Botany 93:295-301.

$\rightarrow$ Jensen, K. B., Y. F. Zhang, and D. R. Dewey. 1990. Mode of pollination of perennial species of the Triticeae in relation to genomically defined genera. Canadian Journal of Plant Science 70:215-225.

$\rightarrow$ Karron, J. D., and R. J. Mitchell. 2012. Effects of floral display size on male and female reproductive success in Mimulus ringens. Annals of Botany 109:563-570.

$\rightarrow$ Koelewijn, H. P., and M. P. H. Hunscheid. 2000. Intraspecific variation in sex allocation in hermaphroditic Plantago coronopus (L.). Journal of Evolutionary Biology 13:302-315.

$\rightarrow$ Lloyd, D. G. 1980. Sexual strategies in plants. 3. A quantitative method for describing the gender of plants. New Zealand Journal of Botany 18:103-108.

Love, A., and H. E. Connor. 1982. Grasses of New Zealand. 2. Relationships and taxonomy of New Zealand wheatgrasses. New Zealand Journal of Botany 20:169-186.

McKone, M. J., C. P. Lund, and J. M. O’Brien. 1998. Reproductive biology of two dominant prairie grasses (Andropogon gerardii and Sorghastrum nutans, Poaceae): male-biased sex allocation in windpollinated plants? American Journal of Botany 85:776-783.

Peng, X. J., K. Wang, C. F. Hu, Y. L. Zhu, T. Wang, J. Yang, J. P. Tong, et al. 2010. The mitochondrial gene orfH79 plays a critical role in impairing both male gametophyte development and root growth in CMS-Honglian rice. BMC Plant Biology 10:125.

Ralphs, M. H., D. Cook, D. R. Gardner, and D. S. Grum. 2011. Transmission of the locoweed endophyte to the next generation of plants. Fungal Ecology 4:251-255.

Rodriguez, R. J., J. F. White, A. E. Arnold, and R. S. Redman. 2009. Fungal endophytes: diversity and functional roles. New Phytologist 182:314-330.

Rudgers, J. A., M. E. Afkhami, M. A. Rua, A. J. Davitt, S. Hammer, and V. M. Huguet. 2009. A fungus among us: broad patterns of endophyte distribution in the grasses. Ecology 90:1531-1539.

Rudgers, J. A., and A. L. Swafford. 2009. Benefits of a fungal endophyte in Elymus virginicus decline under drought stress. Basic and Applied Ecology 10:43-51. 
$\rightarrow$ Sachs, J. L., U. G. Mueller, T. P. Wilcox, and J. J. Bull. 2004. The evolution of cooperation. Quarterly Review of Biology 79:135160.

$\rightarrow$ Saha, M. C., C. A. Young, and A. A. Hopkins. 2009. Genetic variation within and among wildrye (Elymus canadensis and E. virginicus, populations from the southern Great Plains. Crop Science 49:913922.

$\rightarrow$ Sakai, A., and S. Sakai. 2003. Size-dependent ESS sex allocation in wind-pollinated cosexual plants: fecundity vs. stature effects. Jour nal of Theoretical Biology 222:283-295.

$\rightarrow$ Sanderson, M. A., R. H. Skinner, J. Kujawski, and M. van der Grinten. 2004. Virginia wildrye evaluated as a potential native cool-season forage in the northeast USA. Crop Science 44:1379-1384.

$\rightarrow$ Schardl, C. L. 2010. The epichloae, symbionts of the grass subfamily Pooideae. Annals of the Missouri Botanical Garden 97:646-665.

$\rightarrow$ Schärer, L. 2009. Tests of sex allocation theory in simultaneously hermaphroditic animals. Evolution 63:1377-1405.

$\rightarrow$ Sinclair, J. P., J. Emlen, and D. C. Freeman. 2012. Biased sex ratios in plants: theory and trends. Botanical Review 78:63-86.

$\rightarrow$ Stehlik, I., J. Friedman, and S. C. H. Barrett. 2008. Environmental influence on primary sex ratio in a dioecious plant. Proceedings of the National Academy of Sciences of the USA 105:10847-10852.

$\rightarrow$ Tanaka, A., M. J. Christensen, D. Takemoto, P. Park, and B. Scott. 2006. Reactive oxygen species play a role in regulating a fungus- perennial ryegrass mutualistic interaction. Plant Cell 18:10521066.

Turelli, M. 1994. Evolution of incompatibility-inducing microbes and their hosts. Evolution 48:1500-1513.

Vitale, J. J., D. C. Freeman, L. A. Merlotti, and M. Dalessandro. 1987. Patterns of biomass allocation in Spinacia oleracea (Chenopodiaceae) across a salinity gradient: evidence for a niche separation. American Journal of Botany 74:1049-1054.

Wang, Z. Y., Y. X. Ge, M. Scott, and G. Spangenberg. 2004. Viability and longevity of pollen from transgenic and nontransgenic tall fescue (Festuca arundinacea) (Poaceae) plants. American Journal of Botany 91:523-530.

$\rightarrow$ Welty, R. E., M. D. Azevedo, and T. M. Cooper. 1987. Influence of moisture content, temperature, and length of storage on seed germination and survival of endophytic fungi in seeds of tall fescue and perennial ryegrass. Phytopathology 77:893-900.

$\rightarrow$ Werren, J. H., L. Baldo, and M. E. Clark. 2008. Wolbachia: master manipulators of invertebrate biology. Nature Reviews Microbiology 6:741-751.

Yule, K. M., T. E. X. Miller, and J. A. Rudgers. Forthcoming. Costs, benefits, and loss of vertically transmitted symbionts affect host population dynamics. Oikos.

Natural History Editor: Mark A. McPeek 